\title{
Pathologic Epithelial and Anterior Corneal Nerve Morphology in Early-Stage Congenital Aniridic Keratopathy
}

Ulla Eden, Per Fagerholm, Reza Danyali and Neil Lagali

\section{Linköping University Post Print}

N.B.: When citing this work, cite the original article.

Original Publication:

Ulla Eden, Per Fagerholm, Reza Danyali and Neil Lagali, Pathologic Epithelial and Anterior Corneal Nerve Morphology in Early-Stage Congenital Aniridic Keratopathy, 2012, Ophthalmology (Rochester, Minn.), (119), 9, 1803-1810.

http://dx.doi.org/10.1016/j.ophtha.2012.02.043

Copyright: Elsevier http://www.elsevier.com/

Postprint available at: Linköping University Electronic Press http://urn.kb.se/resolve?urn=urn:nbn:se:liu:diva-86136 
Pathologic epithelial and anterior corneal nerve morphology in early-stage congenital aniridic keratopathy

Ulla Edén MD PhD, Per Fagerholm MD PhD, Reza Danyali MSc, Neil Lagali PhD

Department of Ophthalmology, Institute for Clinical and Experimental Medicine Faculty of Health Sciences, Linköping University, 58183 Linköping, Sweden

None of the authors have any conflict of interest in the work presented. The authors have no proprietary or commercial interest in any materials discussed in this article.

Financial support: A European Union Marie Curie Fellowship to NL. Funding support from Crown Princess Margareta's Foundation for the Visually Impaired, the Swedish Eye Fund, Carmen and Bertil Regnérs Foundation, and David and Beth Dahlins Foundation to UE. Support from King Gustav V and Queen Victoria's Freemasons Foundation, the County Council of Östergötland, and the Association of the Blind in Östergötland to PF. The funding organizations had no role in the design or conduct of this research.

This article contains online-only material. The following should appear online-only: Table 1, Table 2, Figure 1, Figure 2, Figure 3, Figure 6.

Running head: Pathologic morphology in aniridic keratopathy

Corresponding author for reprints:

Ulla Edén

Department of Ophthalmology, Institute for Clinical and Experimental Medicine Linköping University 58183 Linköping, Sweden

E-mail: ulla.eden@gmail.com 


\section{ABSTRACT}

Objective: To document clinical and morphologic corneal findings in the early stages of congenital aniridic keratopathy in Swedish families.

Design: Prospective, observational, comparative case series.

Participants: 16 eyes of 16 subjects with congenital aniridic keratopathy and a clear central cornea, and 6 eyes from six healthy controls (unaffected relatives). Nine of the 16 with aniridia came from 5 families with a documented familial history of aniridia.

Methods: Detailed ophthalmic examinations included best spectacle-corrected visual acuity (BSCVA), tear film production, tear break-up time, corneal touch sensitivity, intraocular pressure measurement, ultrasound pachymetry, slit lamp biomicroscopy, and laser-scanning in-vivo confocal microscopy (IVCM).

Main Outcome Measures: Confirmed stage of aniridic keratopathy, clinical parameters of cornea and tear film (visual acuity, sensitivity, corneal thickness, tear production and break-up time), and the morphologic status of corneal epithelium, subbasal nerves, and limbal Palisades of Vogt.

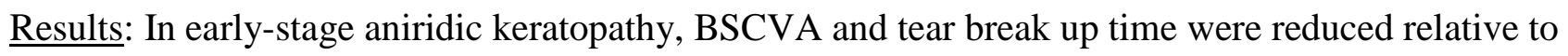
controls $(\mathrm{P}<0.001$ for both $)$, and corneal thickness was increased $(\mathrm{P}=0.01)$. Inflammatory dendritic cells were present in the central epithelium in aniridia, with significantly increased density relative to controls $(\mathrm{P}=0.001)$. Discrete focal opacities in the basal epithelial region were present in 5 of 11 aniridia cases, in an otherwise clear cornea. Opacities were associated with dendritic cells and harbored structures presumed to be goblet cells. Subbasal nerves were extremely dense in three aniridia cases, and a prominent whorl pattern of nerves and epithelial cells was observed in one case. Normal limbal palisade morphology was absent in aniridia but present in controls.

Conclusions: Early-stage aniridic keratopathy is characterized by development of focal opacities in the basal epithelium, altered subbasal nerves, infiltration of the central epithelium by dendritic cells, 
as well as tear film instability, increased corneal thickness and degradation of limbal palisade architecture. These findings may help to elucidate the pathogenesis of aniridic keratopathy. Financial Disclosure(s): The authors have no proprietary or commercial interest in any materials discussed in this article.

Congenital aniridia is an autosomal dominant inherited sight-threatening disease, most often appearing as an isolated eye disorder. It is caused by mutations in the PAX6 gene (chromosome $11 \mathrm{p})$, the master gene of the development of the eye ${ }^{1}$. The most obvious sign of aniridia is a pronounced absence of the iris ${ }^{2}$, although the degree of absence can vary. Aniridia is often associated with severe visual impairment mainly due to deficient development of the retina, particularly of the macular region ${ }^{3}$. The mean best spectacle-corrected visual acuity (BSCVA) in one cohort ${ }^{4}$ was 20/100. Other causes of further visual impairment are glaucoma, cataract development and keratopathy. Glaucoma is frequent, and has been found in more than $40 \%$ of the patients. ${ }^{5}$ Glaucoma diagnosis may be affected by a markedly increased central corneal thickness that could compromise measurements of intraocular pressure ${ }^{6}$. Cataract has additionally been found in $60 \%$ of patients. ${ }^{5}$ Aniridia related keratopathy (ARK) is a severe, sight threatening complication causing chronic irritation. In one cohort of 124 patients, some degree of ARK was found in $80 \%$ of the eyes, and signs of ARK were seen as early as two years after birth ${ }^{5,7}$. In ARK, a progression of conjunctivalization can eventually extend over the entire corneal surface. Parallel to ocular surface changes, the chronic irritation progresses. It has been shown that glaucoma, cataract and corneal surgery can accelerate the conjunctivalization process ${ }^{5,8}$. Much of the knowledge of corneal pathophysiology in aniridia has been gained by studying Pax6 +/- knock-out mice whose phenotype resembles aniridia in the human eye. ${ }^{9}$ The genetic defect influences the regulation of limbal stem cells leading to a breakdown of the barrier 
function, resulting in conjunctiva invading the corneal surface. The corneal epithelium is affected by the Pax6 gene defect, ${ }^{10}$ and epithelial cells in Pax6+/- mice show an increased proliferation and decreased differentiation. ${ }^{11}$ The cytoskeleton constantly restructures and cell junctions are defective ${ }^{12}$. Moreover, in the mouse model epithelial cells are sensitive to oxidative stress ${ }^{13}$, show an increased apoptosis and an abnormal wound healing response, the latter also related to abnormalities in the cell surface glycoconjugates. ${ }^{14}$

Although a progressive conjunctivalization of an initially clear central cornea is the hallmark of ARK, little is known about the status of the transparent cornea at the cellular level in the early stages. We hypothesized that the central and mid-peripheral cornea, which appears normal by slit-lamp biomicroscopy in early-stage ARK, could provide insights into the pathogenesis of ARK under cellular level examination by high resolution laser-scanning in vivo confocal microscopy (IVCM). In addition to examination of cells and nerves of the transparent cornea, IVCM was also performed to assess the morphological state of the limbal palisades region for evidence of structures normally associated with the limbal stem cell niche. ${ }^{15-18}$

\section{MATERIALS AND METHODS}

\section{$\underline{\text { Study Criteria and Subjects }}$}

All subjects with aniridia had participated in a previous study of congenital aniridia in Sweden and Norway. ${ }^{4,5}$ In that study, a total of 124 aniridia patients (79 in Sweden and 45 in Norway) were traced and recorded. From the Swedish cohort, 16 subjects were recruited for the present study, based on a practical limitation of those residing in regions surrounding the two academic hospitals where full examinations could be conducted. Subjects were specifically selected to study early-stage aniridia, and underwent a more detailed ophthalmic examination including for the first time, tear film measurements and cell, nerve, and stem cell assessment of the 
cornea in vivo. To be included in the study, subjects needed to have a transparent central corneal region concomitant with an early stage of aniridic keratopathy (Table 1 and Figure 1, available at http://aaojournal.org.).Unaffected family members served as healthy controls and were chosen based on criteria of good general health without requiring medication, and without a disease known to affect the eyes. Nine subjects in the study had an inherited, congenital aniridia, and belonged to five different families. Five healthy controls were recruited from three of these families. Seven additional subjects had a sporadic aniridia (i.e., none of their relatives had aniridia). The father of one boy with sporadic aniridia was included in the control group. All subjects in the study gave informed consent prior to enrolment. The study was conducted in accordance with the Helsinki Declaration of ethical principles for the medical community, and with permission from the Ethics Committee of Linköping.

\section{Examinations}

All subjects underwent a full ophthalmic examination. Examinations were bilateral if possible, and where data from both eyes was available, only the right eye was included in the study. Examinations included testing of best spectacle-corrected visual acuity (BSCVA) and refraction using a Snellen chart. Tear production was quantified by Shirmers test without anaesthesia, where normal tear secretion should moisten greater than $10 \mathrm{~mm}$ of the strip in five minutes. Corneal sensitivity was assessed by contact esthesiometry (Cochet-Bonnet esthesiometer, Luneau Ophthalmologie, France), with a nylon thread length of $60 \mathrm{~mm}$ considered as normal. Tear break-up time (BUT) was used to evaluate the stability of the tear film. Only the tear film break-up on the clear part of the cornea was considered, and a BUT of more than 10s was regarded as normal. Intraocular pressure (IOP) was measured with applanation tonometry, which was used to check the present glaucoma treatment, if any, or to indicate new cases with increased IOP. 
Slit-lamp microscopy examination was performed to classify the degree of corneal changes in aniridia (Table 1 and Fig 1, available at http://aaojournal.org.). The grading scale ${ }^{5}$ is an adaptation of earlier described scales. ${ }^{19,20}$ Corneas were documented by digital photography in the slit lamp microscope and by anterior segment optical coherence tomography (ASOCT, Visante, Zeiss), and central corneal thickness was measured with ultrasound pachymetry (TOMEY SP-2000). The Orbscan II topographer (Bausch \& Lomb) was used to document corneal topography and in-vivo confocal microscopy (IVCM; HRT3-RCM, Heidelberg Engineering, Germany) was used to evaluate cellular changes in the cornea including quantification of subbasal nerve density ${ }^{21}$ and Langerhans/dendritic cell density in the central cornea. ${ }^{22,23}$ IVCM images were coded to blind examiners to the subject's diagnosis (aniridia or healthy control). For dendritic cell density, only mature dendritic cells, consisting of cell bodies and processes, were counted, as an indication of the presence of antigen-presenting cells involved in inflammation. ${ }^{23,24}$ For quantification, from each subject, clear, high-contrast images of the central subbasal nerve plexus with the greatest number of visible nerves and the greatest number of visible dendritic cells were selected. These images were used to assess subbasal nerve density and mature dendritic cell density, respectively. Nerve tracing and cell counting functions in Image J software ${ }^{25}$ were used, as described previously. ${ }^{21}$ Density values were determined independently by two trained observers, and the mean value between observers was reported. The inferior limbal region was also examined by IVCM to assess morphology in the region of the limbal Palisades of Vogt. ${ }^{15,16}$

\section{$\underline{\text { Statistical analysis }}$}

Mean BSCVA was calculated using the logmar scale, and logmar values were used for comparison of aniridia to controls. Visual acuity values were converted to the Snellen equivalent for reporting. Independent t-tests or the Mann-Whitney test were used to compare clinical and morphologic parameters between groups, with the Mann-Whitney test reserved for cases where data was not 
normally distributed. Correlation of clinical parameters with stage of aniridic keratopathy, and correlation of subbasal nerve density with corneal touch sensitivity was assessed using Pearson's test for normally distributed data, and the Spearman Rank Order correlation otherwise. All statistics were performed with commercial software (SigmaStat 3.5; Systat Software Inc., Chicago IL) where a twotailed level of $\alpha=0.05$ was considered significant.

\section{RESULTS}

\section{Patient Characteristics}

The pedigrees of the five families examined are given in Figure 2, available at http://aaojournal.org. Results of the clinical examinations, indexed by a code indicating pedigree position, are given in Table 2, available at http://aaojournal.org. Due to light sensitivity or ocular surface irritation in some subjects with aniridia, non-compliance during examination resulted in incomplete clinical data. The mean age of aniridia subjects was 31y (range 18-52y) and healthy controls was $37 y$ (range 11-57y). Nine subjects with aniridia were males and seven were females. Of the six healthy controls, five were females.

\section{Ophthalmic examination results}

Mean BSCVA in aniridia was 20/160 despite clear central corneas. In addition to deficient development of the retina, leading to macular and foveal defects causing decreased visual acuity, three aniridic subjects had cataract disturbing vision, and four had glaucoma. Mean BSCVA in controls (20/19) was significantly better ( $\mathrm{P}<0.001$, Mann-Whitney). Tear production by Schirmer's test was similar in both aniridia (mean $22.8 \mathrm{~mm}$, range: $4-35 \mathrm{~mm}$ ) and control (mean $25.5 \mathrm{~mm}$, range: $11-35 \mathrm{~mm}$ ) groups $(\mathrm{P}=0.53$, Mann-Whitney); however, the range was wider in aniridia, with one subject having a value of $4 \mathrm{~mm}$. Tear BUT was below $10 \mathrm{~s}$ in 13 of 14 aniridic corneas tested, with a mean of 7.9s, significantly shorter than the mean BUT of $17.7 \mathrm{~s}$ in controls $(\mathrm{P}<0.001$, t-test $)$. 
Corneal touch sensitivity did not differ between groups $(\mathrm{P}=0.10$, Mann-Whitney); however, sensitivity was normal $(60 \mathrm{~mm})$ in all controls but ranged from $35-60 \mathrm{~mm}$ in aniridia. Central corneal pachymetry showed significantly thicker corneas in aniridia (mean $635 \mu \mathrm{m}$, range $587-738 \mu \mathrm{m}$ ) than in healthy controls (mean $557 \mu \mathrm{m}$, range $491-609 \mu \mathrm{m} ; \mathrm{P}=0.01$, t-test).

Slit lamp examination revealed nine eyes with stage 1 and seven eyes with stage 2 aniridic keratopathy. Age was significantly correlated to the stage of keratopathy, with stage 1 subjects being younger (median 21y) than stage 2 (median 38y; $\mathrm{P}=0.004$, Spearman Rank Order correlation). BSCVA, tear film production, BUT, touch sensitivity, central corneal thickness and IOP did not vary with stage 1 or 2 of keratopathy.

\section{$\underline{\text { In vivo confocal microscopy }}$}

In five of 16 aniridia cases, it was not possible to obtain useful in vivo confocal microscope images of the cornea due to a severe bilateral nystagmus.

\section{Corneal epithelium}

In the central cornea, epithelial wing cell layers in 9 of 11 aniridia cases examined contained small hyper-reflective inclusions indicative of inflammatory (presumably dendritic) cells, while these inclusions were absent in healthy controls (Figure 3, available at http://aaojournal.org.). At the level of the basal epithelium, 5 of 11 with aniridia exhibited discrete, focal opacities distributed in the midperipheral to central cornea. Opacities were round to polygonal in shape, and varied in size from $10-$ $100 \mu \mathrm{m}$, although large, confluent opacities several hundred microns in size were also observed (Figure 4). The opacities were often observed in the same depth layer as subbasal nerves. No opacities were observed in controls.

Dendritic cells 
Mature dendritic cells were present in the central subbasal nerve plexus in 11 of 11 aniridia cases examined and in five of six controls. The density of mature dendritic cells in aniridia (median 94 cells $/ \mathrm{mm}^{2}$ ), however, was significantly greater than in controls (median 19 cells $/ \mathrm{mm}^{2} ; \mathrm{P}=0.001$, Mann-Whitney). The proportion of subjects with normal $\left(<32\right.$ cells $\left./ \mathrm{mm}^{2}\right)$ and pathologic $(>64$ cells $/ \mathrm{mm}^{2}$ ) dendritic cell density ${ }^{22}$ is given in Figure 5, along with images depicting the appearance of the mature dendritic cells.

\section{Subbasal nerves}

Central corneal subbasal nerve density in aniridia (median $25,270 \mu \mathrm{m} / \mathrm{mm}^{2}$, range $4798-51,227$ $\mu \mathrm{m} / \mathrm{mm}^{2}$ ) and control (median $26,434 \mu \mathrm{m} / \mathrm{mm}^{2}$, range $21,211-30,680 \mu \mathrm{m} / \mathrm{mm}^{2}$ ) groups did not differ ( $\mathrm{P}=0.73$; Mann-Whitney), however, a wide range was apparent in aniridia. In particular, three of 11 aniridia cases had extremely dense nerves, with density exceeding $45,000 \mu \mathrm{m} / \mathrm{mm}^{2}$ (Figure 6 , available at http://aaojournal.org.). No correlation between subbasal nerve density and corneal touch sensitivity by contact esthesiometry could be found.

In one aniridia case (C V:4) with prominent subbasal nerves and a high subbasal nerve density $\left(45,397 \mu \mathrm{m} / \mathrm{mm}^{2}\right)$, patterns were noted in the epithelial basal and wing cell layers, that appeared to correspond with the underlying nerve fiber bundles of the subbasal nerve plexus. In this case, a montage of IVCM images was made in successive depth planes, to depict the pattern of epithelial cells and underlying nerves in the region of the infero-central whorl of subbasal nerves, which was particularly prominent (Figure 7). Nerve tracing and subsequent overlay of the tracings on the epithelial cells using Matlab software (The Math Works Inc., Natick MA, USA) confirmed an exact match between subbasal nerve and epithelial cell positions in the whorl region, strongly suggesting their co-ordinated centripetal movement.

\section{Limbal palisades}


The inferior limbal region of the cornea was chosen to assess the in vivo morphology of the structures of the limbal palisades, as an indicator of the status of the limbal stem cell niche. ${ }^{17}$ In 4 of 6 healthy controls, imaging of the limbal palisades region was possible due to varying subject tolerance of the imaging procedure. In these corneas, normal morphologic features of the limbal epithelium were observed, including palisade ridges and focal stromal projections (Figure 8). Imaging of the inferior corneal limbal region was possible in-nine cases of aniridia. None of these corneas, however, had a distinct limbal palisades region, and all had abnormal cell morphology. In one case, palisade ridge-like features and small focal stromal projections were observed (Figure 8), although these features appeared to be abnormally developed. In the remaining cases, however, a total absence of these features was noted, with the limbal region instead appearing conjunctivalized with vessels, leukocytes, and opaque tissue (Figure 8).

\section{DISCUSSION}

The goal of this study was to document clinical and morphologic corneal findings in the early stages of aniridic keratopathy. In one earlier study, slit lamp examination showed absence of palisades of Vogt and superficial corneal vascularization in 16/16 aniridic eyes, 9 of which had clear central cornea. ${ }^{19}$ Based on this result and findings in other studies, ${ }^{5,26,27}$ we believe that under careful examination, most if not all cases of congenital aniridia can be found to have some degree of keratopathy.

In the present study, clinical examination findings in early-stage ARK suggested Meibomian gland dysfunction or a pathologic lipid layer leading to tear film instability, echoing earlier findings. ${ }^{26}$ Central corneal changes also included reduced touch sensitivity in several cases and thickening of the cornea in most, also confirming earlier reports of increased corneal thickness in congenital aniridia in otherwise clear, normal-appearing central corneas. ${ }^{28,29}$ 
With the clinical status established, laser-scanning in vivo confocal microscopy (IVCM) examination now enables us to add more detail to the early ARK picture. Although corneal epithelial changes such as inflammatory ${ }^{27}$ and goblet cell ${ }^{19,27}$ invasion accompany conjunctivalisation in severe stages of ARK, in this study dendritic cell invasion of wing and basal epithelial cell layers (to a pathologic density level) was observed at an early stage. Additionally, presumed goblet cells were observed in association with focal basal epithelial opacities extending into the mid-peripheral cornea. In an earlier report, goblet cells were found on the peripheral cornea corresponding to stage 2 ARK in our scale, and it was further suspected that a chronic inflammation was present. ${ }^{26}$ These observations are consistent with our in vivo dendritic and goblet cell findings. While dendritic cell density in aniridia exceeded the density in controls and in previous reports of normal subjects, ${ }^{22,23}$ the value was below the density reported in clinically inflamed corneas. ${ }^{23}$ The absence of overt signs of inflammation in this study suggests the mature dendritic cell population is indicative of a chronic, subclinical form of inflammation in early-stage ARK.

Just under half of early-stage ARK cases exhibited discrete focal opacities at the level of the basal epithelium. The opacities were distributed peripherally and some extended to the central cornea, but corneal tissue remained transparent outside these focal regions. Larger, confluent opacities observed in the peripheral cornea in some cases morphologically resembled conjunctival epithelium (Figure 4), and some opacities harbored presumed goblet cells. Based on these observations, it is hypothesized that opacification occurs not only by a gradual invasion of conjunctival tissue from the periphery, but also by 'islands' of opaque tissue within a clear cornea spreading to form larger, confluent opaque regions.

The transition of stratified epithelium into keratinized epithelium (or squamous metaplasia) has been noted in earlier studies by impression cytology, ${ }^{19,26}$ and several cases of progressive corneal opacities in aniridia have been reported, with opacities described as nonhealing epithelial defects, persistent mucous plaques, and pannus formations with inflammatory cells. ${ }^{27,30}$ In this study, we noted the 
location of these early-stage opacities as just anterior to and possibly within Bowman's layer, and further noted a conjunctival phenotype of opacities. Interestingly, subbasal nerves were also observed in close association with the opacities, appearing to originate from or terminate at opacities. Whether the nerves play a role in the development of the epithelial opacities or conversely whether the opacities influence nerve guidance and function is unknown. In a Pax6 mouse model of ARK, no evidence of neurotrophic deficiency could be found in heterozygous Pax6 corneas, however, the model differed developmentally from human cases and no corneal opacities were reported in the mice. ${ }^{31}$

IVCM assessment of the subbasal nerve plexus revealed a marked increase in nerve density in the central cornea of three patients compared to the control group and to other healthy human corneas assessed by the same laser-scanning IVCM technique. ${ }^{32,33}$ This finding is notably contradictory to one report of decreased subbasal nerve density in heterozygous Pax6 mice. ${ }^{31}$ We present, however, the first subbasal nerve density values in human cases, and the highest subbasal nerve density observed in vivo to date. Recent ex vivo studies of nerves in human cornea samples have shed new light on the architecture and distribution of subbasal nerves in the normal cornea. ${ }^{34,35}$ Notably, in six immunohistochemically-stained whole mount human donor corneas, the mean subbasal nerve density in the central cornea was measured to be $45,940 \mu \mathrm{m} / \mathrm{mm}^{2}$, a value twice as high as reported by laser-scanning IVCM. ${ }^{34}$ It was suggested that the immunohistochemical staining method was sensitive enough to detect subbasal nerves of small diameter and interconnecting axons that are normally too faint to be detected by IVCM. ${ }^{34}$ The findings in the present study therefore suggest that subbasal nerve density is pathologically high in a proportion of aniridia patients and/or that thin nerves and interconnecting axons are rendered more visible in the aniridic cornea in vivo. These possibilities could arise from several factors observed in Pax6 mouse models, including: reduced adhesion between epithelial cells ${ }^{12,36}$ facilitating the proliferation or penetration of subbasal nerves normally confined to narrow intercellular spaces; the presence of pathologic epithelial cells ${ }^{12,14,37}$ 
potentially resulting in reduced light scatter from cells and cell junctions making nerves more visible; and a thinner epithelium with fewer cell layers ${ }^{9,11}$ improving visibility/contrast or condensing more epithelial nerves into a given plane.

A prominent spiral pattern in the epithelial cells observed in one case had an exact correlation with the whorl pattern of underlying subbasal nerves in the inferocentral cornea. The aforementioned epithelial cell defects may have rendered this correlation more visible in the aniridic cornea; however, it may also indicate a general correspondence of epithelial cell and subbasal nerve migration in the normal cornea. Interestingly, a coordinated centripetal movement of epithelial cells and nerves has been postulated in several studies. ${ }^{38,39}$ The present study provides the first evidence in human corneas of an exact correspondence of epithelial cell and subbasal nerve patterns of movement, however, as noted in a recent study,${ }^{34}$ the mechanisms orchestrating this motion still remain unclear.

In vivo findings in the limbal palisades region in aniridia were consistent with absence of the limbal stem cell niche and early conjunctivalisation of the limbal region. Several reports of IVCM examination of the limbal palisades in normal and stem cell deficient patients has revealed the detailed in vivo morphology of this region thought to harbor epithelial stem cells. ${ }^{15-18}$ The most notable characteristics are prominent ridge structures, circular focal stromal projections and limbal crypts residing between adjacent ridges at their base. Some or all of these structures were observed in healthy controls, but notably, the structures were present in an altered form in one case of aniridia. It is not known in what form the stem cell niche is present in congenital aniridia or whether it deteriorates over time, however, our findings indicate that this niche could exist at least morphologically to some degree in early ARK. Whether the morphology alone can serve as a prognostic indicator of stem cell presence or function is unknown. An earlier report, however, noted visible palisades in the early stages of ARK which later became masked by keratinization, ${ }^{26}$ and in another study using IVCM, absence of palisade ridges and focal stromal projections in the limbus in 
a series of eight patients with limbal stem cell deficiency was noted, four of whom had aniridia. ${ }^{17}$ Further study of the stem cell niche in aniridia is warranted.

Some limitations of this study were the small subgroup of patients who could be examined by in vivo confocal microscopy, the cross-sectional design (precluding longitudinal progression data), and possible selection bias in examining only subjects from certain regions and only corneas tolerant to the imaging procedure. In future studies, a larger patient population, which exists in Sweden and Norway, ${ }^{4}$ could be examined, and additionally longitudinal follow-up could be reported. In summary, in this study the examination of transparent corneas in the early stages of aniridic keratopathy revealed tear film instability, subclinical epithelial inflammation, a pattern of early opacification in the subepithelial region of the clear cornea, dense subbasal nerves, and degradation or absence of the limbal stem cell niche. A complex interplay between limbal and central epithelium, subbasal nerves, inflammatory cells, and conjunctiva seems to characterize the progressive degradation of corneal transparency in patients with aniridic keratopathy.

\section{Acknowledgement}

The authors wish to thank Anette Dellby, registered nurse, for preparing the familial pedigrees. 


\section{$\underline{\text { References }}$}

1. Prosser J, van Heyningen V. PAX6 mutations reviewed. Hum Mutat 1998;11:93-108.

2. Churchill A, Booth A. Genetics of aniridia and anterior segment dysgenesis. Br J Ophthalmol 1996;80:669-73.

3. Tremblay F, Gupta SK, De Becker I, et al. Effects of PAX6 mutations on retinal function: an electroretinographic study. Am J Ophthalmol 1998;126:211-8.

4. Edén U, Iggman D, Riise R, Tornqvist K. Epidemiology of Aniridia in Sweden Norway. Acta Ophthalmol Scand 2008;86:727-9.

5. Edén U, Riise R, Tornqvist K. Corneal involvement in Aniridia. Cornea 2010;29:10961102 .

6. Brandt JD, Casuso LA, Budenz DL. Markedly increased central corneal thickness: an undiagnosed finding in congenital aniridia. Am J Ophthalmol 2004;137:348-50.

7. Edén U, Beijar C, Riise R, Tornqvist K. Aniridia among children and teenagers in Sweden and Norway. Acta Ophthalmol Scand 2008;86:730-4.

8. Tsai JH, Freeman JM, Chan CC, et al. A Progressive Anterior Fibrosis Syndrome in Patients with Postsurgical Congenital Aniridia. Am J Ophthalmol 2005;140:1075-9.

9. Ramaesh T, Collinson JM, Ramaesh K, et al. Corneal abnormalities in Pax+/- small eye mice mimic human aniridia-related keratopathy. Invest Ophthalmol Vis Sci 2003;44:18718.

10. Ramaesh K, Ramaesh T, Dutton GN, Dhillon B. Evolving concepts on the pathogenetic mechanisms of aniridia related keratopathy. Int J Biochem Cell Biol 2005;37:547-57.

11. Ramaesh T, Ramaesh K, Collinson JM, et al. Developmental and cellular factors underlying corneal epithelial dysgenesis in the $\mathrm{Pax}^{+/-}$mouse model of aniridia. Exp Eye Res 2005;81:224-35.

12. Ou J, Lowes C, Collinson JM. Cytoskeletal and Cell Adhesion Defects in Wounded and pax6+/Corneal Epithelia. Invest Ophthalmol Vis Sci 2010;51:1415-23.

13. Ou J, Walczysko P, Kucerova R, et al. Chronic wound state exacerbated by oxidative stress in $\mathrm{Pax6}^{+/-}$aniridia-related keratopathy. J Pathol 2008;215:421-30.

14. Kucerova R, Ou J, Lawson D, et al. Cell surface glycoconjugate abnormalities and corneal epithelial wound healing in the Pax6+/- mouse model of aniridia-related keratopathy. Invest Ophthalmol Vis Sci 2006;47:5276-82.

15. Messmer EM, Mackert MJ, Zapp DM, Kampik A. In vivo confocal microscopy of normal conjunctiva and conjunctivitis. Cornea 2006;25:781-8. 
16. Patel DV, Sherwin T, McGhee CNJ. Laser scanning in vivo confocal microscopy of the normal human corneoscleral limbus. Invest Ophthalmol Vis Sci 2006;47:2823-7.

17. Shortt AJ, Secker GA, Munro PM, et al. Characterization of the limbal epithelial stem cell niche: novel imaging techniques permit in vivo observation and targeted biopsy of limbal epithelial stem cells. Stem Cells 2007;25:1402-9.

18. Takahashi N, Chikama T, Yanai R, Nishida T. Structures of the corneal limbus detected by laser-scanning confocal biomicroscopy as related to the Palisades of Vogt detected by slit-lamp microscopy. Jpn J Ophthalmol 2009; 53:199-203.

19. Nishida K, Kinoshita S, Ohashi Y, et al. Ocular surface abnormalities in aniridia. Am J Ophthalmol 1995;120:368-7.

20. Lopez-Garcia JS, Garcia-Lozano I, Rivas L, Martinez-Garchitorena J. Congenital aniridia keratopathy treatment. Arch Soc Esp Oftalmol 2006;81:435-44.

21. Lagali NS, Germundsson J, Fagerholm P. The role of Bowman's layer in corneal regeneration after phototherapeutic keratectomy: a prospective study using in vivo confocal microscopy. Invest Ophthalmol Vis Sci. 2009; 50;4192-8.

22. Zhivov A, Stave J, Vollmar B, Guthoff R. In vivo confocal microscopic evaluation of Langerhans cell density and distribution in the normal human corneal epithelium. Graefe's Arch Clin Exp Ophthalmol 2005;243:1056-61.

23. Mastropasqua L, Nubile M, Lanzini M, et al. Epithelial dendritic cell distribution in normal and inflamed human cornea: in vivo confocal microscopy study. Am J Ophthalmol 2006;142:736-44.

24. Hamrah P, Liu Y, Zhang Q, Dana MR. The corneal stroma is endowed with a significant number of resident dendritic cells. Invest Ophthalmol Vis Sci 2003;44:581-9.

25. Rasband, W.S., ImageJ, U. S. National Institutes of Health, Bethesda, Maryland, USA, http://imagej.nih.gov/ij/, 1997-2011. URL accessed on Feb 17, 2011.

26. Jastaneiah S, Al-Rajhi AA. Association of aniridia and dry eyes. Ophthalmology 2005;112:1535-40.

27. Gomes JAP, Eagle RC, Gomes AK, et al. Recurrent keratopathy after penetrating keratoplasty for aniridia. Cornea 1996;15:457-62.

28. Brandt JD, Casuso LA, Budenz DL. Markedly increased central corneal thickness: an undiagnosed finding in congenital aniridia. Am J Ophthalmol 2004;137:348-50.

29. Whitson JT, Liang C, Godfrey DG, et al. Central corneal thickness in patients with congenital aniridia. Eye Cont Lens 2005;31:221-4.

30. Saidkasimova S, Roberts F, Jay J. Mucous plaque keratitis associated with aniridia keratopathy. Eye 2005;19:926-8. 
31. Leiper L, Ou J, Walczysko P, et al. Control of patterns of corneal innervation by PAX6. Invest Ophthalmol Vis Sci 2009;50:1122-8.

32. Patel DV, Ku JY, Johnson R, et al. Laser scanning in vivo confocal microscopy and quantitative aesthesiometry reveal decreased corneal innervation and sensation in keratoconus. Eye 2009;23:586-92.

33. Niederer RL, Perumal D, Sherwin T, McGhee CNJ. Corneal innervation and cellular changes after corneal transplantation: an in vivo confocal microscopy study. Invest Ophthalmol Vis Sci 2007;48:621-6.

34. Marfurt CF, Cox J, Deek S, Dvorscak L. Anatomy of the human corneal innervation. Exp Eye Res 2010;90:478-92.

35. Al-Aqaba MA, Fares U, Suleman H, et al. Architecture and distribution of human corneal nerves. Br J Ophthalmol 2010;94:784-9.

36. Davis J, Duncan MK, Robison WG, Piatigorsky J. Requirement for Pax6 in corneal morphogenesis: a role in adhesion. J Cell Sci 2003;116:2157-67.

37. Ramaesh T, Ramaesh K, Leask R, et al. Increased apoptosis and abnormal wound healing responses in the heterozygous Pax6 ${ }^{+/-}$mouse cornea. Invest Ophthalmol Vis Sci 2006;47:1911-7.

38. Patel DV, McGhee CNJ. In vivo laser scanning confocal microscopy confirms that the human corneal sub-basal nerve plexus is a highly dynamic structure. Invest Ophthalmol Vis Sci 2008;49:3409-12.

39. Collinson JM, Chanas SA, Hill RE, West JD. Corneal development, limbal stem cell function, and corneal epithelial cell migration in the Pax $6^{+-}$mouse. Invest Ophthalmol Vis Sci 2004;45:1101-8. 
Table 1. Scale used to grade the stage of aniridic keratopathy.

\begin{tabular}{ll} 
Stage & \multicolumn{1}{c}{ Description } \\
\hline $0 \quad$ Clear cornea \\
$1 \quad \begin{array}{l}\text { Some mudding of the periphery indicating ingrowth of } \\
\text { vessels }\end{array}$ \\
$\begin{array}{l}\text { Clouding with ingrowth of vessels in the whole } \\
\text { circumference of the periphery but not disturbing } \\
\text { visual acuity }\end{array}$ \\
$\begin{array}{l}\text { Difficulties to examine the retina because of marked } \\
\text { central keratopathy with engagement of the corneal } \\
\text { stroma and centripetal ingrowth of vessels }\end{array}$ \\
$4 \quad \begin{array}{l}\text { Opaque cornea } \\
5\end{array} \quad \begin{array}{l}\text { End stage: total cornea converted into an irregular } \\
\text { structure without any of the original layers visible }\end{array}$
\end{tabular}


Table 2. Ophthalmologic examination findings in aniridia and healthy controls.

\begin{tabular}{|c|c|c|c|c|c|c|c|c|c|}
\hline Group & $\begin{array}{l}\text { Patient } \\
\text { Code }\end{array}$ & $\begin{array}{l}\text { Age } \\
(y)\end{array}$ & $\begin{array}{c}\text { Snellen } \\
\text { BSCVA } \\
(20 /)\end{array}$ & $\begin{array}{c}\text { Schirmer } \\
\text { length } \\
(\mathrm{mm})\end{array}$ & $\begin{array}{c}\text { BUT } \\
(\mathrm{s})\end{array}$ & $\begin{array}{l}\text { Esthesiometry } \\
\text { (mm) }\end{array}$ & $\begin{array}{l}\text { CCT } \\
(\mu \mathrm{m})\end{array}$ & $\begin{array}{c}\text { IOP } \\
(\mathrm{mm} \mathrm{Hg})\end{array}$ & $\begin{array}{l}\text { ARK } \\
\text { Stage }\end{array}$ \\
\hline \multirow{16}{*}{ Aniridia } & A II:3 & 60 & 400 & 6 & 3 & 60 & \multirow[t]{2}{*}{640} & & 2 \\
\hline & A III:2 & 36 & 100 & 35 & 9 & 50 & & & 2 \\
\hline & A III:5 & 41 & 154 & 30 & 4 & & \multirow[t]{3}{*}{738} & \multirow[t]{3}{*}{20} & 2 \\
\hline & A IV:4 & 17 & 400 & 4 & 10 & & & & 1 \\
\hline & $B V: 2$ & 27 & 200 & & & & & & 2 \\
\hline & B V:4 & 18 & 200 & 26 & 6 & 50 & 641 & 18 & 1 \\
\hline & C V:4 & 21 & 100 & 35 & & 60 & \multirow[t]{2}{*}{602} & & 1 \\
\hline & D III:4 & 33 & 200 & 29 & 5 & 60 & & 16 & 2 \\
\hline & E II:1 & 52 & 40 & & 10 & 60 & 617 & 15 & 1 \\
\hline & F II & 21 & 100 & 25 & 10 & 50 & \multirow[t]{2}{*}{683} & \multirow[t]{2}{*}{15} & 1 \\
\hline & $\mathrm{G}$ & 20 & 25 & 30 & 5 & 60 & & & 1 \\
\hline & $\mathrm{H}$ & 39 & 2000 & 30 & 5 & 35 & 599 & 30 & 2 \\
\hline & I & 25 & 154 & 20 & 10 & 60 & 668 & 16 & 1 \\
\hline & $\mathrm{J}$ & 29 & & 8 & 10 & 60 & 587 & 16 & 1 \\
\hline & $\mathrm{K}$ & 38 & 100 & 18 & 14 & 60 & 592 & 14 & 2 \\
\hline & $\mathrm{L}$ & 20 & 200 & & 10 & 45 & 622 & 15 & 1 \\
\hline \multirow{6}{*}{$\begin{array}{l}\text { Healthy } \\
\text { Controls }\end{array}$} & B VI:1 & 11 & 20 & 25 & 11 & 60 & & & 0 \\
\hline & A III:14 & 25 & 20 & 27 & 14 & 60 & \multirow[b]{2}{*}{609} & 14 & 0 \\
\hline & C V:3 & 26 & 20 & 30 & 11 & 60 & & 17 & 0 \\
\hline & C IV:3 & 49 & 20 & 25 & 27 & 60 & 491 & 13 & 0 \\
\hline & C IV:1 & 55 & 20 & 35 & 28 & 60 & 540 & & 0 \\
\hline & FI & 57 & 15 & 11 & 15 & 60 & 588 & 16 & 0 \\
\hline
\end{tabular}

Missing data is due to subject non-compliance and/or difficulty in obtaining an accurate reading. $\mathrm{BSCVA}=$ best spectacle-corrected visual acuity; $\mathrm{BUT}=$ tear film break-up time; $\mathrm{CCT}=$ central corneal thickness; IOP = intraocular pressure; $\mathrm{ARK}=$ aniridia related keratopathy. 


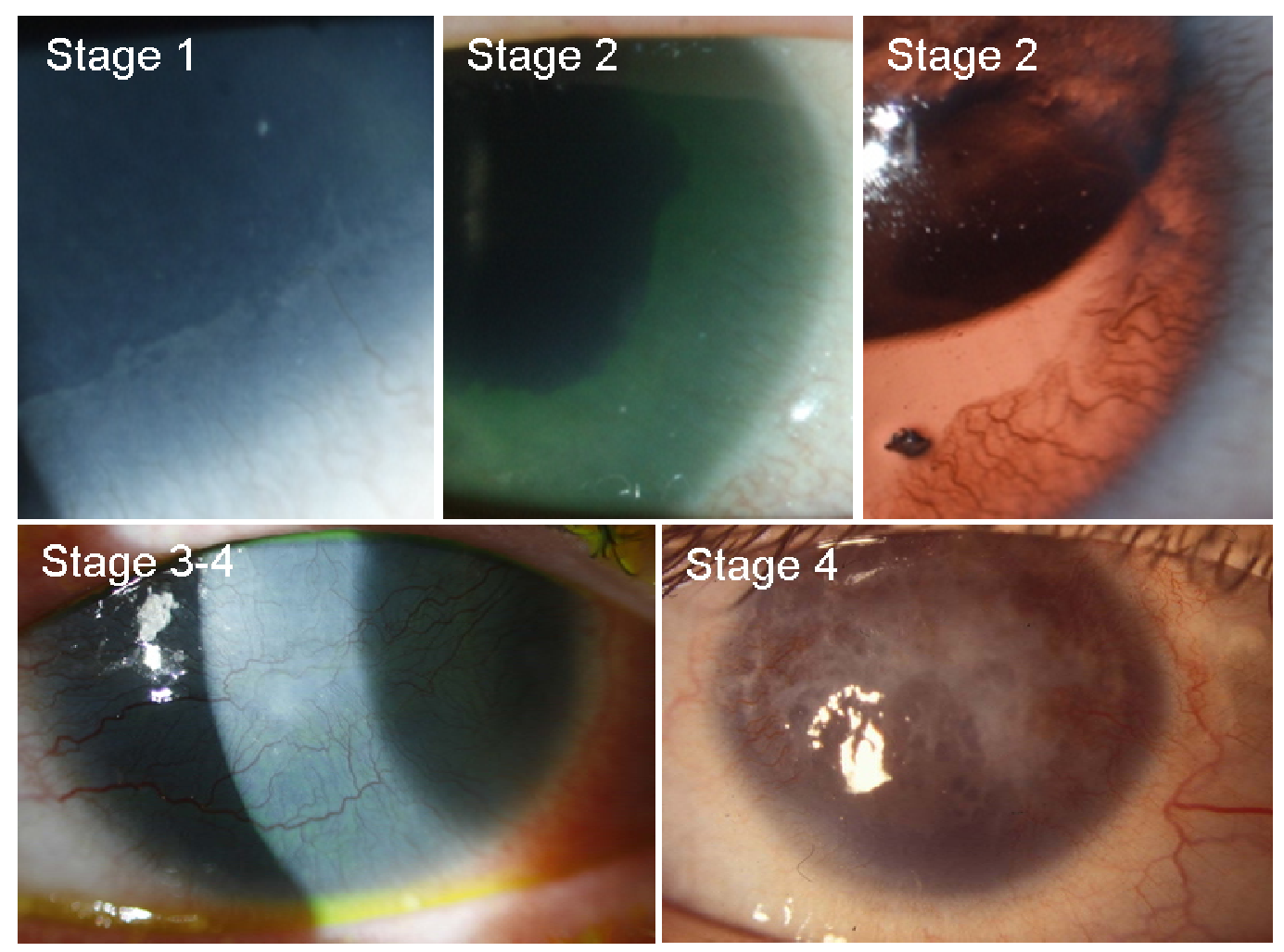

Figure 1. Slit lamp photographs illustrating various stages of aniridic keratopathy. In Stage 1, conjunctival cells and vessels invade the peripheral cornea in a limited region near the limbus. Stage 2 is characterized by peripheral to mid-peripheral conjunctivalization, but with a clear central cornea. Stage 3 includes marked central corneal involvement with vascularization and stromal involvement. Stage 4 is indicated by complete conjunctivalization with an opaque cornea. 

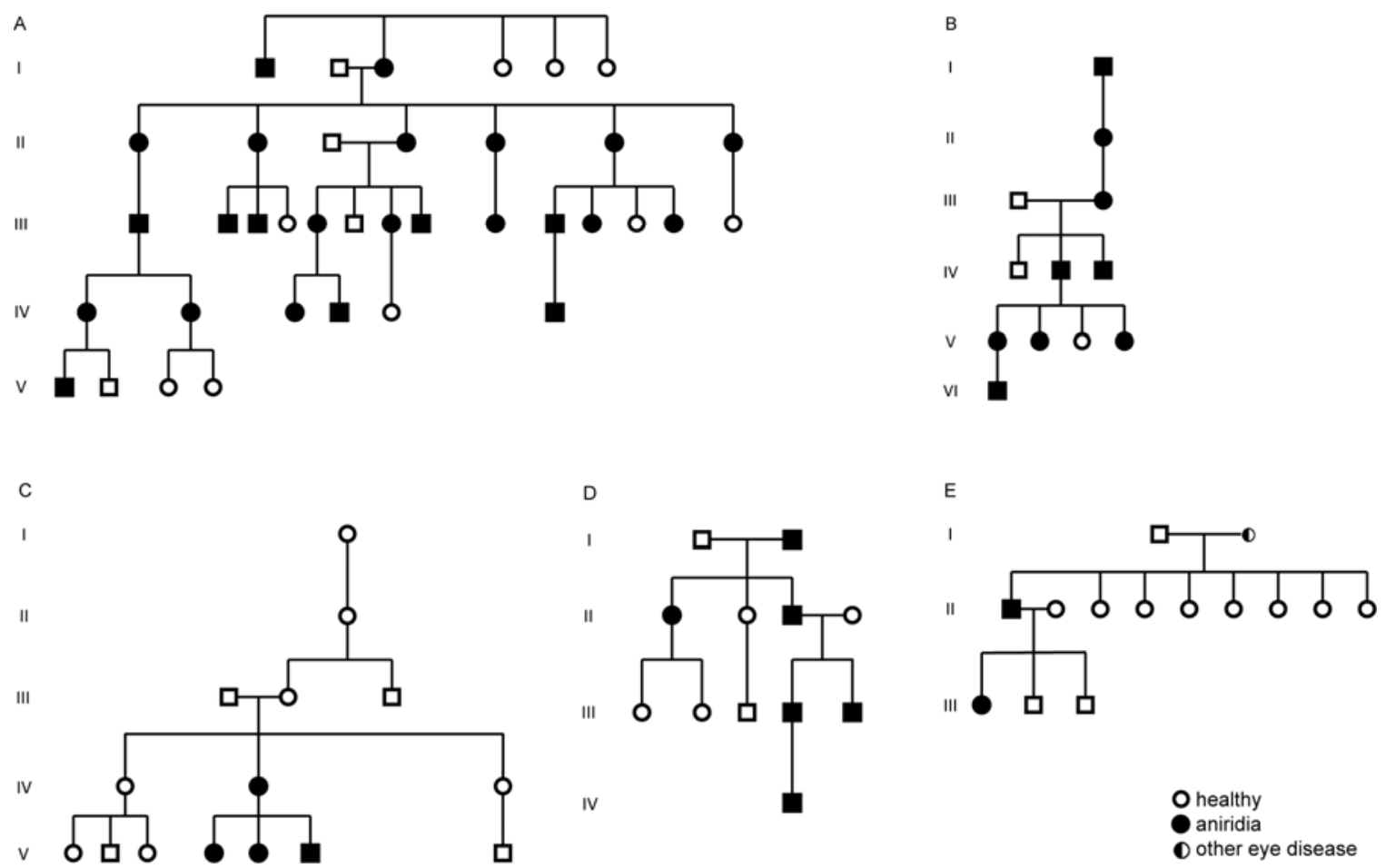

Figure 2. Pedigrees of five of the families with hereditary aniridia examined in this study. The other eye disease in Family E was cataract and glaucoma. 


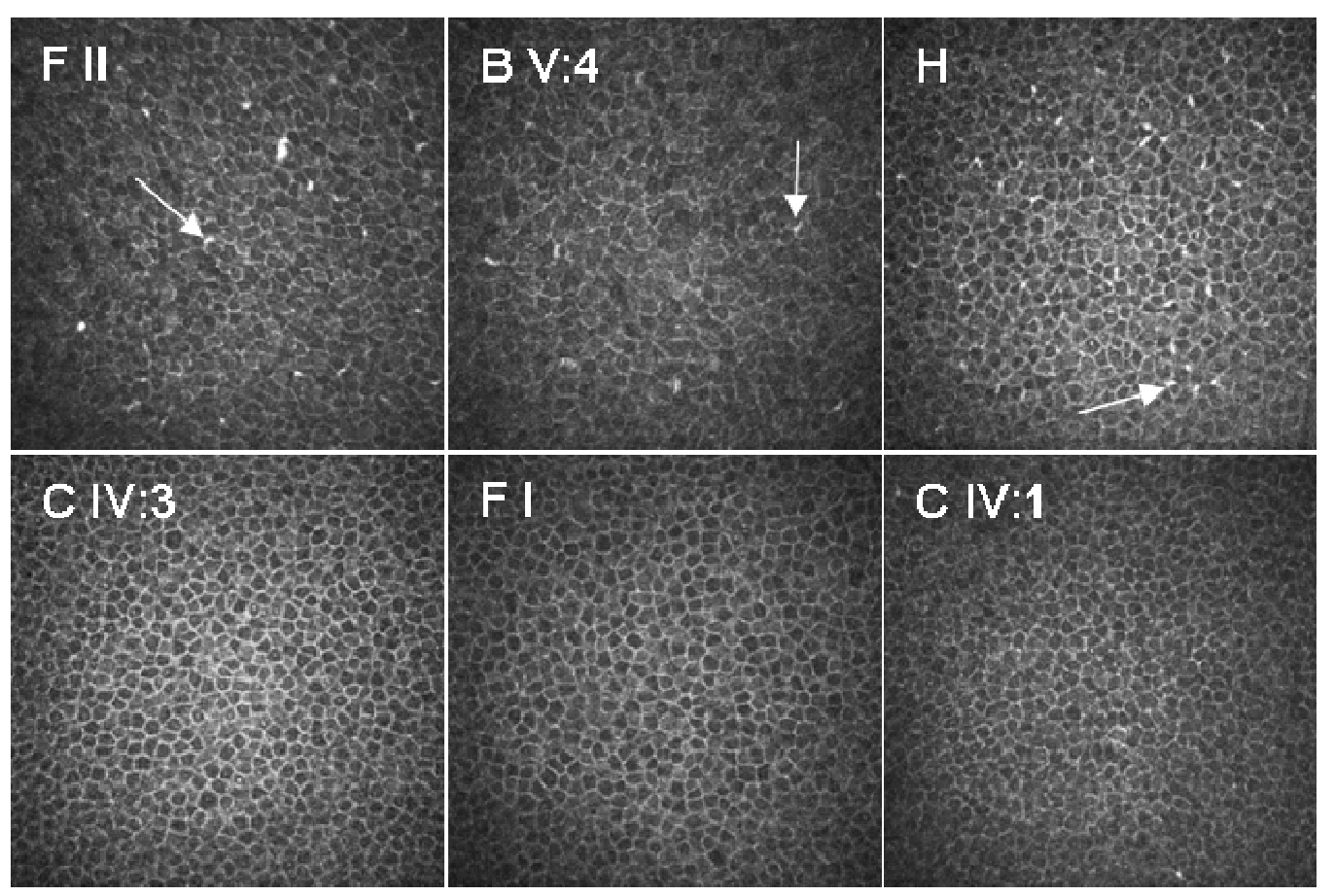

Figure 3. In-vivo appearance of epithelial wing cell morphology in the central cornea in aniridia (top row) and in healthy controls (bottom row). Small, reflective inclusions (arrows) indicate inflammatory dendritic cell presence in the aniridic epithelium, where these inclusions are absent in the control group. All images $400 \times$ $400 \mu \mathrm{m}$. Codes indicate position in the pedigree. 
Figure 5
Click here to download high resolution image
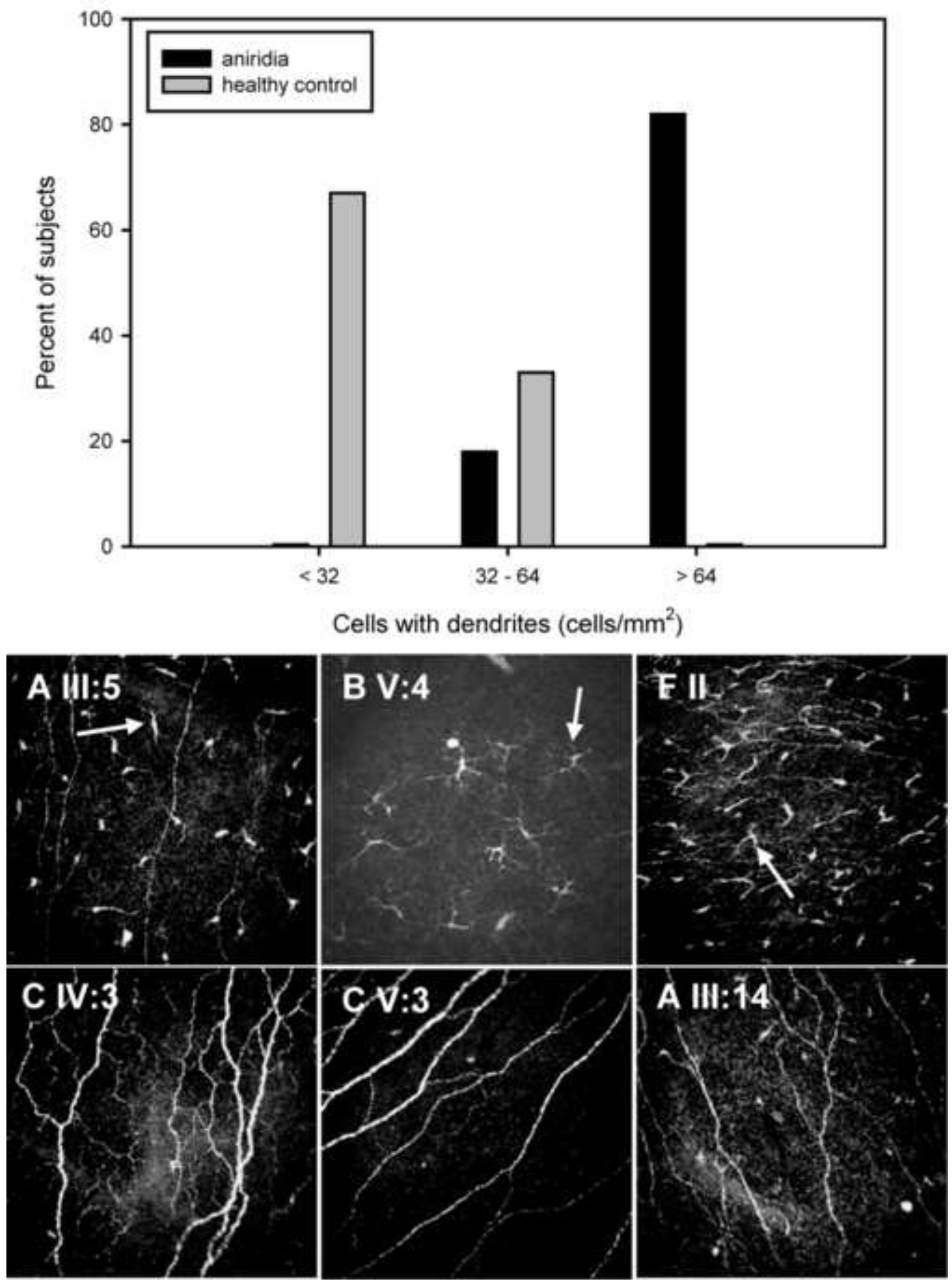

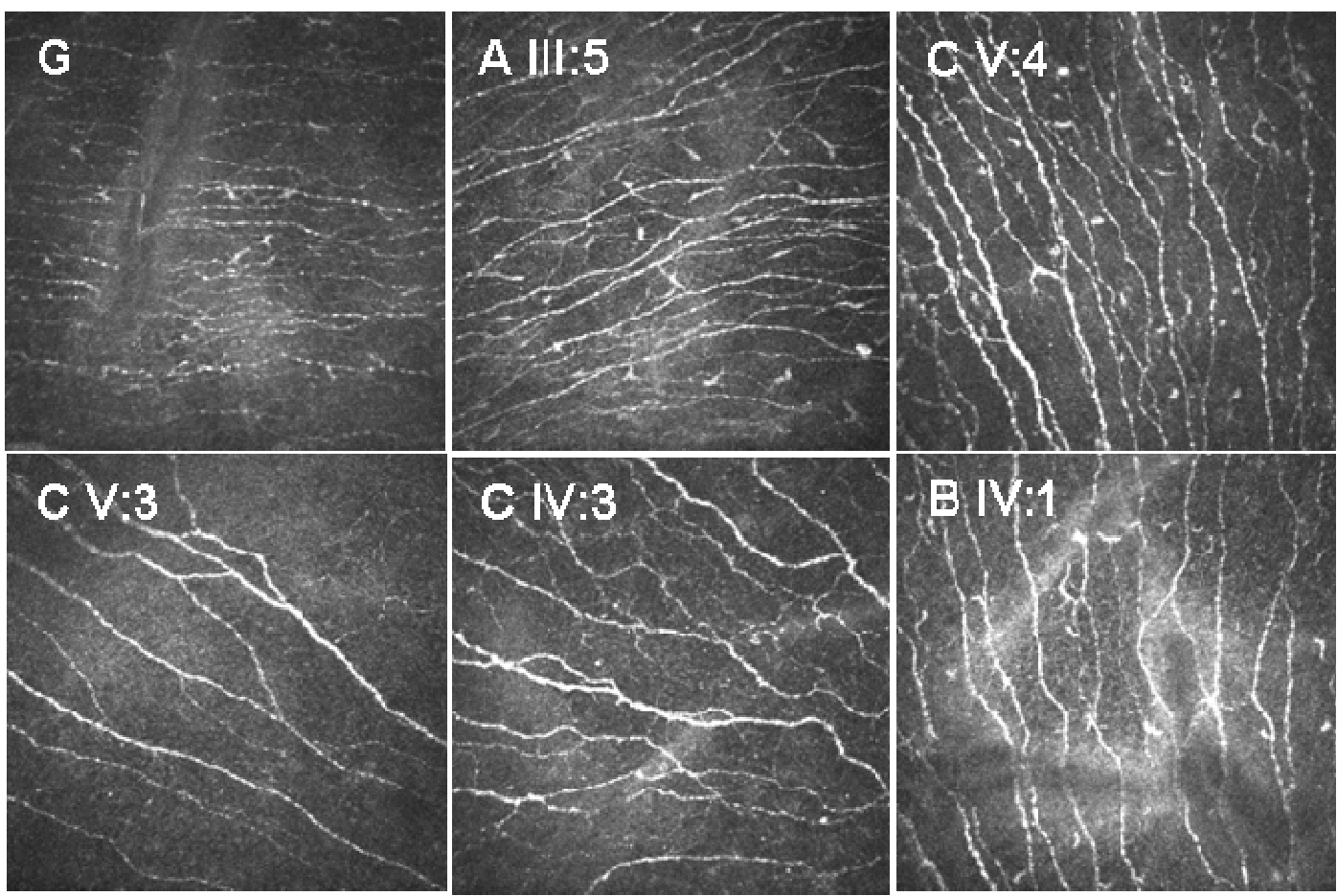

Figure 6. In vivo images of subbasal nerves in the central cornea in aniridia (top row) and in healthy controls (bottom row). The three aniridic corneas with the highest subbasal nerve density (in excess of 45,000 $\mu \mathrm{m} / \mathrm{mm}^{2}$ ) are shown. All images $400 \times 400 \mu \mathrm{m}$. 
Figure 7
Click here to download high resolution image
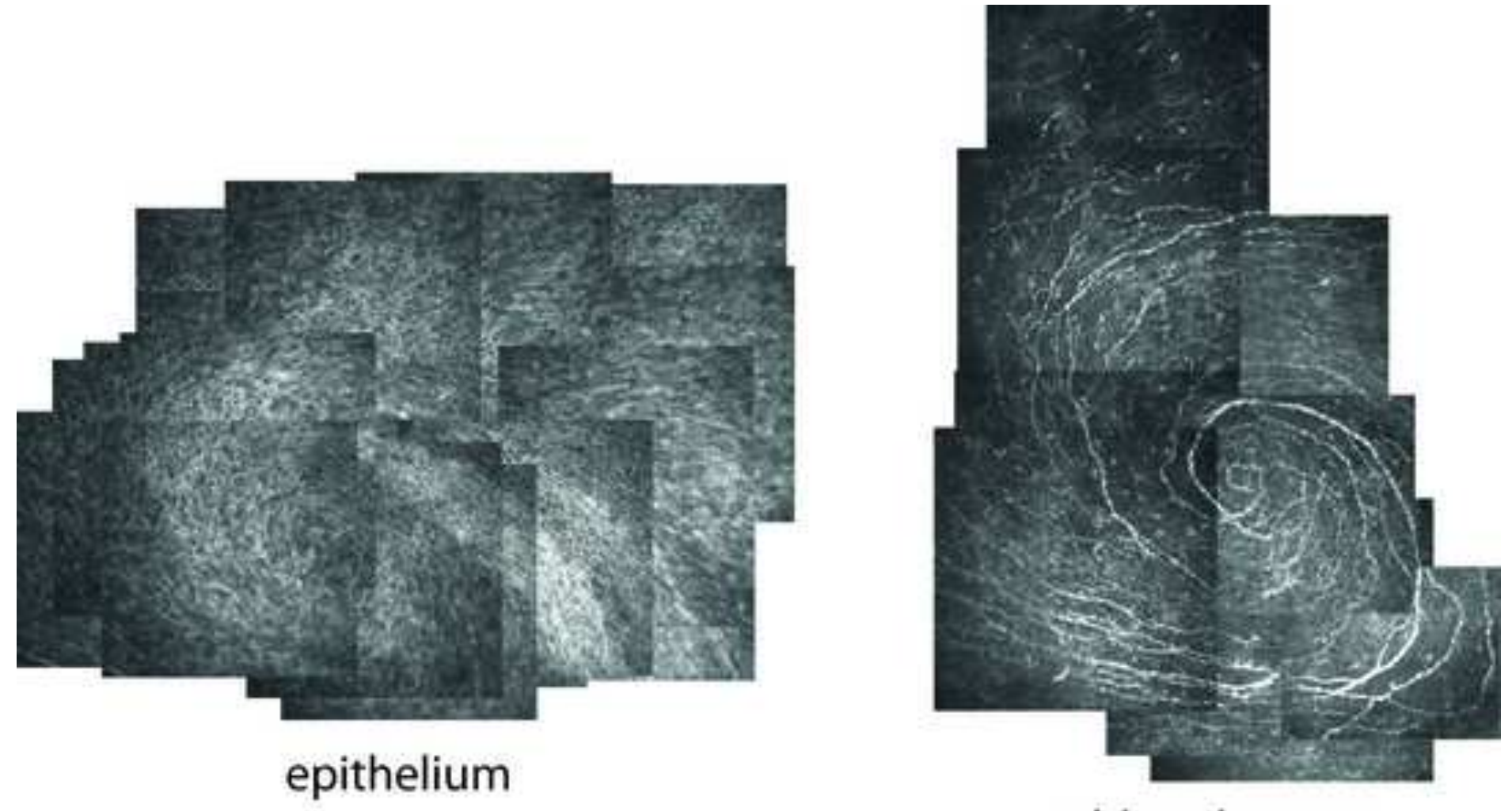

subbasal nerves

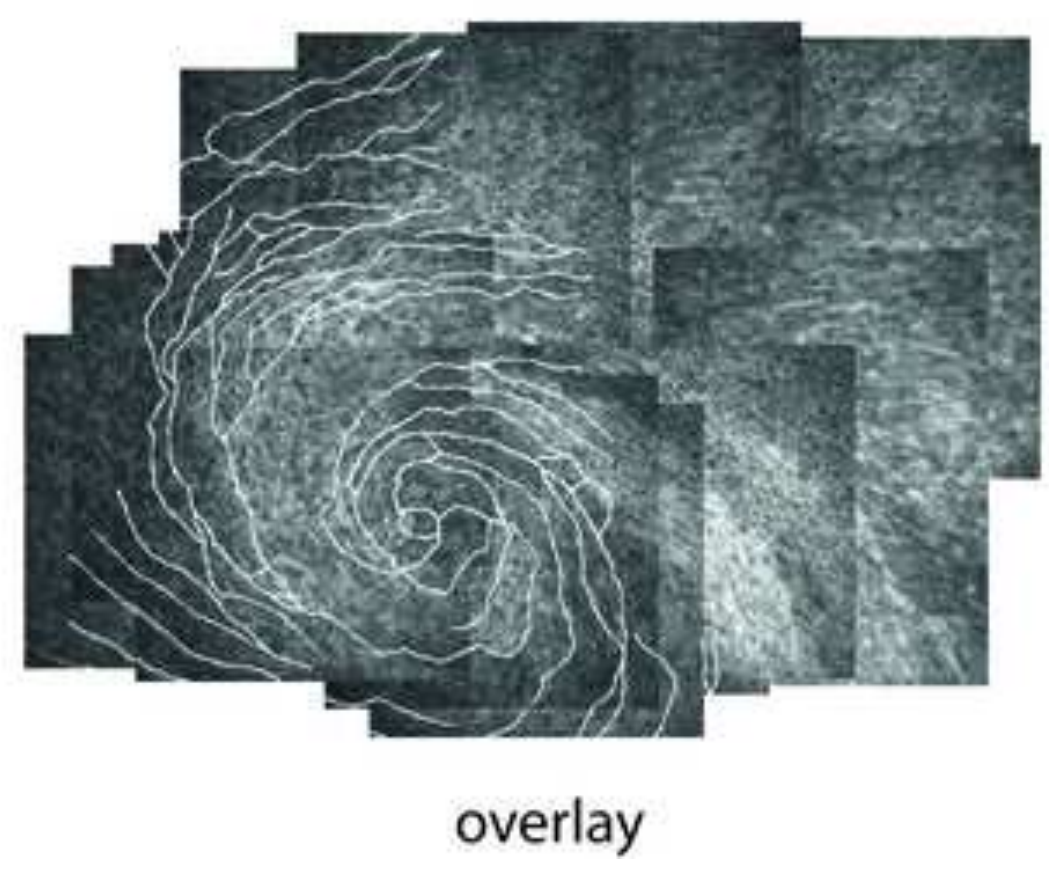




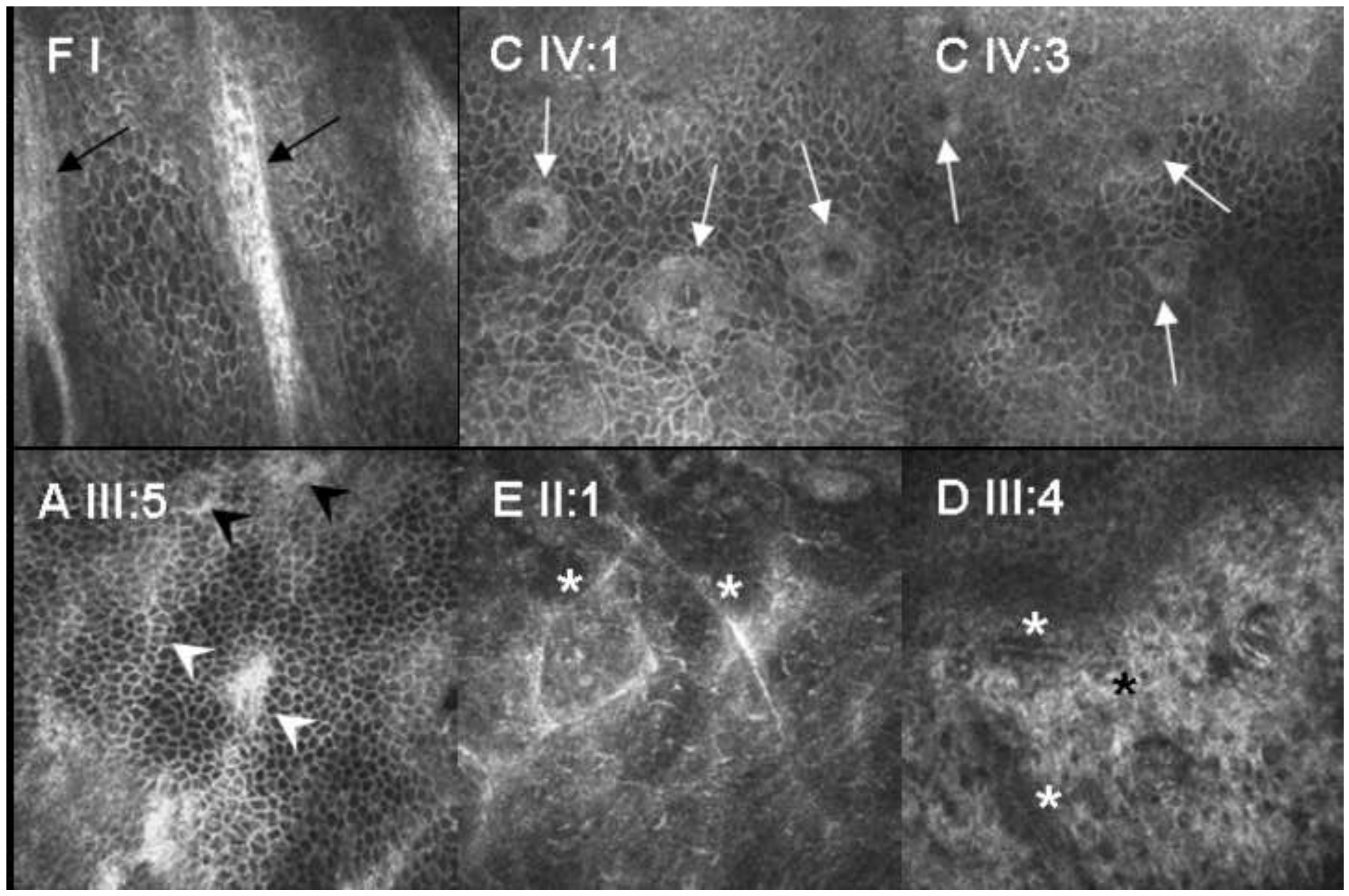

FI

A $111: 5$
EII:1

\section{Civ.s}

\section{III:4}


Figure Legends

Figure 4. In vivo appearance of the basal epithelium in five aniridia cases, indicating the presence of focal opacities of varying size and shape. Opacities were often observed in close proximity to subbasal nerves and dendritic cells (white arrows), and in some cases harboured hyper-reflective cells presumed to be goblet cells (black arrows). Larger, confluent opacities were also observed (asterisk). Morphology of the focal opacities resembled that of conjunctival tissue that extended over the limbus in the corneal periphery (Subject H, black arrows indicate presumed goblet cells). All images $400 \times$ $400 \mu \mathrm{m}$.

Figure 5. Results of dendritic cell analysis by in vivo confocal microscopy. Top: the majority of aniridia cases had a pathologically high density of mature dendritic cells in the central cornea at the level of the basal epithelium, while the majority of healthy controls had a normal dendritic cell density. In vivo images depict mature dendritic cells (white arrows) in the central cornea in aniridia (top row), and mainly immature dendritic cells (cell bodies without long processes, black arrows) in the central corneas of controls (bottom row). All images $400 \times 400 \mu \mathrm{m}$.

Figure 7. A prominent subbasal nerve whorl pattern in one case of aniridia (C V:4) was noted. A similar pattern was noted in the overlying epithelium. When nerve tracings were overlaid on the epithelial montage, a direct and exact match of epithelial cell and nerve patterns was found, suggesting a coordinated centripetal movement. 
Figure 8. In vivo images of the inferior limbal palisades region in healthy controls (top row) and in aniridia (bottom row). Characteristic palisade ridge structures (black arrows) and focal stromal projections (white arrows) were observed in controls. In one aniridia case, abnormal ridge-like features (white arrowheads) and small focal stromal projections (black arrowheads) were observed. In the remaining aniridia cases, palisade structures were absent altogether, and instead vessels (white asterisks), dendritic cells, and reflective conjunctival tissue (black asterisk) were present. All images $400 \times 400 \mu \mathrm{m}$. 